\title{
Pavement performance evaluation for different combinations of temperature conditions and bituminous mixes
}

\author{
M. S. Ranadive ${ }^{1} \cdot$ Anand Tapase $^{1}$
}

Received: 30 May 2016/Accepted: 30 August 2016/Published online: 12 September 2016

(C) Springer International Publishing Switzerland 2016

\begin{abstract}
The effectiveness of 2D axisymmetric finite element analysis in predicting the performance of flexible pavements at different temperatures is illustrated in the present study. The critical parameters are examined for variation in thicknesses and material properties of the bituminous layer, to select the right binder grade of bituminous mixes for the particular climatic condition or the selected temperature profile. To observe the effect of decrement in temperature profile of the under layer on the performance of the pavement, variation in modulus of dense bituminous macadam is analyzed for material properties reported as per IRC: 37-2012. For the modern trucks, which usually have more than $0.800 \mathrm{MPa}$ tyre pressure, the right binder grade of bituminous layer comprising a wearing course and dense bituminous macadam is $1700 \mathrm{MPa}$ for $250 \mathrm{~mm}$-thick bituminous layer. When more stiffer binder is used, drastic change in the value of critical parameters is observed. A reduction of 18.98 and $5.25 \%$ in horizontal tensile strain and vertical compressive strain, respectively, is observed at a $200 \mathrm{~mm}$ thickness of bituminous layer and around 21.12 and $6.72 \%$ in horizontal tensile strain and vertical compressive strain, respectively, at $250 \mathrm{~mm}$ thickness of bituminous layer. As the values of the critical parameters are noticed well within the allowable limits at $200 \mathrm{~mm}$, it is concluded that the use of a stiffer binder for DBM makes the pavement safe as far as fatigue of bituminous layer and rutting in subgrade is
\end{abstract}

Anand Tapase

tapaseanand@gmail.com

M. S. Ranadive

msrtunnel@yahoo.co.in

1 Department of Civil Engineering, College of Engineering, Pune, Maharashtra, India concerned with the reduction in thickness of the bituminous layer even at higher temperature. It is observed that the use of waste plastic/rubber is found in safe limits at $250 \mathrm{~mm}$-thick bituminous layer for the selected condition. It is concluded that the use of too soft a bituminous mix results in lowering the structural capacity of the pavement at high temperatures and too hard bituminous mixes would become brittle at low temperatures.

Keywords Temperature - Modified bituminous mixes · Fatigue $\cdot$ Rutting $\cdot$ Flexible pavement

\section{Introduction}

The growing intensity of commercial vehicles, overloading of trucks beyond double its capacity and change in daily and cyclic temperature and environmental factors have been responsible for reducing the life of the pavement. A factor which causes further concern in India is low pavement temperatures in some parts of the country. Under these conditions, flexible pavements tend to become soft in summer and brittle in winter [1]. The complex characteristic of the present day systems like overloaded modern trucks therefore demands an application of analytical tool which can accommodate all the above said details of the complex system [2].

The abundantly available waste materials such as waste plastic, rubber, e-waste, etc., create problems of its disposal in an eco-friendly way. Investigations in India and abroad have revealed that such type of waste materials which are durable and recyclable can be effectively used in road construction [1,3]. As per the Research Scheme R-55 of MORTH, use of rubber and polymer modified bitumen in bituminous road construction of Central Road Research 
Institute (CRRI) indicates that the wearing course of polymer and rubber-modified bituminous mixes have longer lives. Indian Road Congress (IRC) has formulated IRC codes [1, 4] for the use of waste plastic and rubber in road construction. From the literature, it is observed that the properties of pavements with the bituminous mixes can be improved to meet the requirements of pavement with the incorporation of certain modifiers. To achieve this improvement, it is necessary to add polymers to bituminous mixes. Waste plastic is added to enhance the property of the bituminous mixes resulting in improvement of quality of roads.

In continuation with the investigation related to varying the thickness and material properties of different layers reported in Tapase and Ranadive [5], the present study evaluated the effectiveness of $2 \mathrm{D}$ axisymmetric finite element analysis in predicting the performance of flexible pavements at different temperatures. Such analysis will lead to set a procedure for increasing the scope of using a variety of blends of materials and real field situations which can be checked for its suitability in pavement construction. In the present study, the variation in thicknesses and material properties of bituminous layers at constant thickness of the base layer are examined for selected trial temperatures as per IRC: 37-2012. The values of horizontal tensile strain at the bottom of the bituminous layer and the vertical compressive strain at the top of the subgrade, which are considered as the critical performance parameters of flexible pavement, are evaluated from the analysis.

\section{Pavement composition}

In all, four trial thicknesses $\left(h_{1}\right)$ of the bituminous layer, $100-250 \mathrm{~mm}$ is considered for analysis, wherein the bituminous concrete (BC) top layer of the bituminous mix is kept constant at $50 \mathrm{~mm}$ and dense bituminous macadam (DBM) is varied starting from $50 \mathrm{~mm}$ with an increment of $50 \mathrm{~mm}$ at every trial. As per the Indian conditions, where the average annual pavement temperature of bituminous surfacing is approximately $35{ }^{\circ} \mathrm{C}$, for all the stated trials, the modulus of $\mathrm{BC}$ is taken as $E_{1}=1700 \mathrm{MPa}$ and Poisson's ratio $\left(\mu_{1}\right)=0.35$, which is recommended and incorporated in practice for $\mathrm{BC}$ and $\mathrm{DBM}$ for viscosity grade (VG30) of the bituminous mix as per IRC: 37-2012. Initially, the use of different grades of bituminous mixes starting from too soft a bituminous mix to too hard a bituminous mix including the use of modified bituminous mixes (i.e., mix prepared from the use of waste plastic/ rubber) are taken as first set; secondly, it is assumed that the temperature profile shows a decrement in the underneath layer; so to study the effect of temperature difference on the performance of the pavement, variation in the modulus of DBM is taken for the reported material properties for a $35-20{ }^{\circ} \mathrm{C}$ temperature by a decrement of $5{ }^{\circ} \mathrm{C}$ for each trial for viscosity grade (VG30) of bituminous mix as per IRC: 37-2012. In the present study, the granular base and granular sub-base are treated as a single granular layer of $450 \mathrm{~mm}$ with crushed rock having material property as $E_{2}=450 \mathrm{MPa}, \mu_{2}=0.35$. The base layer material is kept constant throughout the analysis. A uniform pressure of $0.800 \mathrm{MPa}(800 \mathrm{kPa})$ caused by the modern trucks is applied on a circular contact area having a radius of $150 \mathrm{~mm}$ as shown in Fig. 1. The Modulus of various bituminous mixes given in Table 1 is based on the results of extensive laboratory testing as per ASTM: D7369-09 throughout the country which are obtained at different temperatures from 20 to $40{ }^{\circ} \mathrm{C}$ [4]. Variation in a layer of DBM below the wearing course of bituminous mixes starting from lower viscosity-grade bitumen to higher viscosity-grade bitumen, including modified bitumen, are analyzed for various trial increases in temperature as shown in Table 1.

All the above-stated trials are typically checked for their suitability in the pavement section for selected subgrade condition for $E_{3}=80 \mathrm{MPa}$ [3]. If such type of analysis is validated, it will prove to be beneficial to derive useful design charts for any combinations of thicknesses, material properties and field conditions without relying on

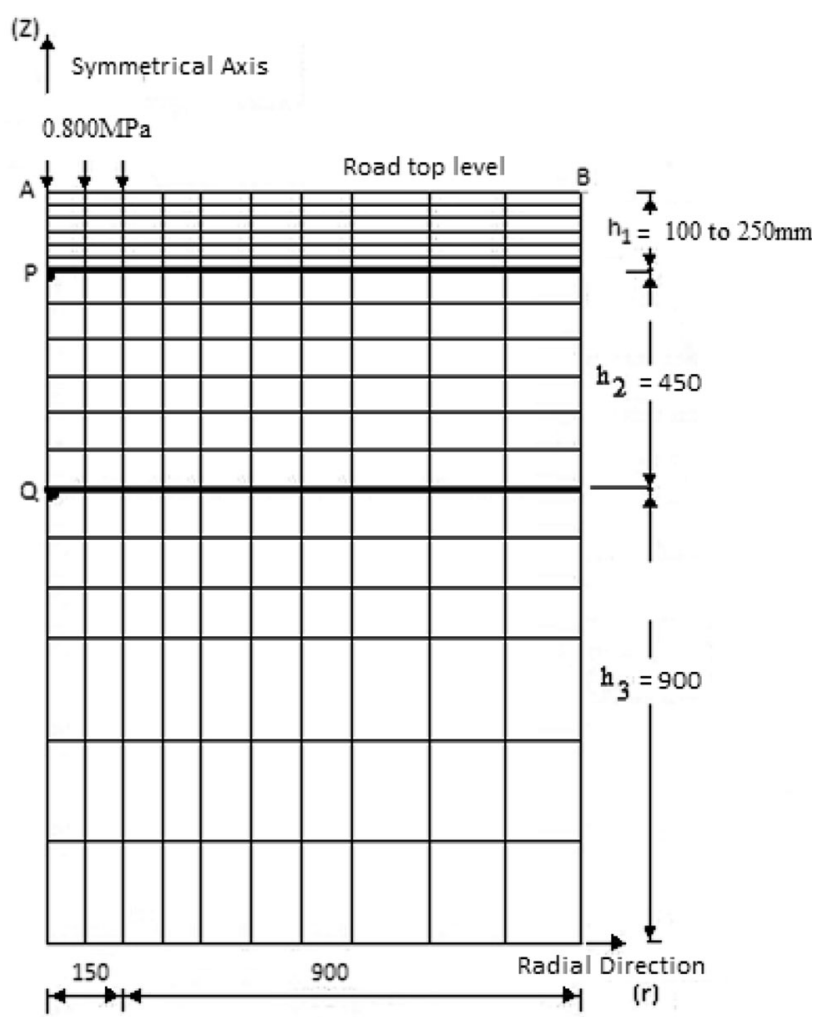

Fig. 1 Finite element idealization of the pavement section (all dimensions are in $\mathrm{mm}$ ) 
Table 1 Variations in resilient modulus of bituminous mixes, $\mathrm{MPa}$, as per IRC: $37-2012[4,6]$

\begin{tabular}{llllll}
\hline Mix type for viscosity grade (VG) & \multicolumn{7}{l}{ Temperature $\left({ }^{\circ} \mathrm{C}\right)$} \\
\cline { 2 - 6 } & 20 & 25 & 30 & 35 & 40 \\
\hline BC and DBM for VG 10 bitumen (MPa) & 2300 & 2000 & 1450 & 1000 & 800 \\
BC and DBM for VG30 bitumen (MPa) & 3500 & 3000 & 2500 & 1700 & 1250 \\
BC and DBM for VG40 bitumen (MPa) & 6000 & 5000 & 4000 & 3000 & 2000 \\
BC and DBM for modified bitumen (MPa) & 5700 & 3800 & 2400 & 1650 & 1300 \\
\hline
\end{tabular}

theoretical/empirical design procedures. These hypothetical thicknesses and material properties are generally considered in practice as per IRC: $37-2012$ [4, 7]; hence, it is an attempt to correlate the present study with the actual field conditions.

\section{Finite element modeling}

In general, the finite element solution technique is adopted through three basic stages of the analysis; those are idealization of the system being investigated, formulation and solution of equations governing the phenomenon and evaluation of the structural response required for undertaking the design process as reported by Tapase and Ranadive [5].

Basically, constitutive laws in the present development are confined toward consideration to only modulus of elasticity and the Poisson's ratio of the materials used in the pavement system being analyzed. The scope for a variety of material types that may be encountered in the built up pavement system are indefinite in number. Similarly, practical useful data can be extracted from available literature $[8,9,10]$ for further investigation, including the elastic modulus and Poisson's ratio.

\section{Finite element idealization}

The finite element idealization for the pavement system being analyzed is developed by means of the four noded quadrilateral elements. Helwany et al. [11] discretized a three-layered pavement system with the right boundary at a distance of about eight times the loaded radius. Sinha et al. [12] located the right boundary which is more than seven times the radius $150 \mathrm{~mm}$ of the applied load. In the present work, the total thickness of the pavement is taken as $1450-1600 \mathrm{~mm}$ as per the trial thickness of the bituminous layer starting from 100 to $250 \mathrm{~mm}$ with an increment of $50 \mathrm{~mm}$ having $25 \mathrm{~mm}$ thickness of each sublayer, and the base layer is kept constant at $450 \mathrm{~mm}$ having sublayer $75 \mathrm{~mm}$ thick and subgrade is taken up to $900 \mathrm{~mm}$ (Fig. 1).

\section{Boundary conditions}

The nodes at the bottom of the subgrade are restrained in both radial $(r)$ and axial $(z)$ directions as shown in Fig. 1. The nodes over the axis of the symmetry are restrained in the radial direction. It is assumed that due to the indefinite lateral extent of the pavement section, the nodes over the extreme vertical face of the pavement, i.e., at a horizontal distance of $1050 \mathrm{~mm}$ from the centerline of the wheel loading, do not suffer radial displacements $[8,12,13]$. Hence, these nodes are treated as restrained in the radial $(r)$ direction.

\section{Results and discussion}

In continuation with the investigation reported by Tapase and Ranadive [5], here at selected trial temperatures and various trial conditions of different component layers, the critical performance parameters are examined for variation in the stiffness of naturally occurring and waste materials in a bituminous layer of flexible pavement. In Fig. 2, a plot of the bituminous mixes at various temperatures of VG 10 , VG 30, VG 40 and modified bitumen versus horizontal tensile strain at the bottom of the bituminous layer is considered for analysis. Its effect on the horizontal tensile strain at the bottom of the bituminous layer for various hypothetical temperatures is also considered for analysis.

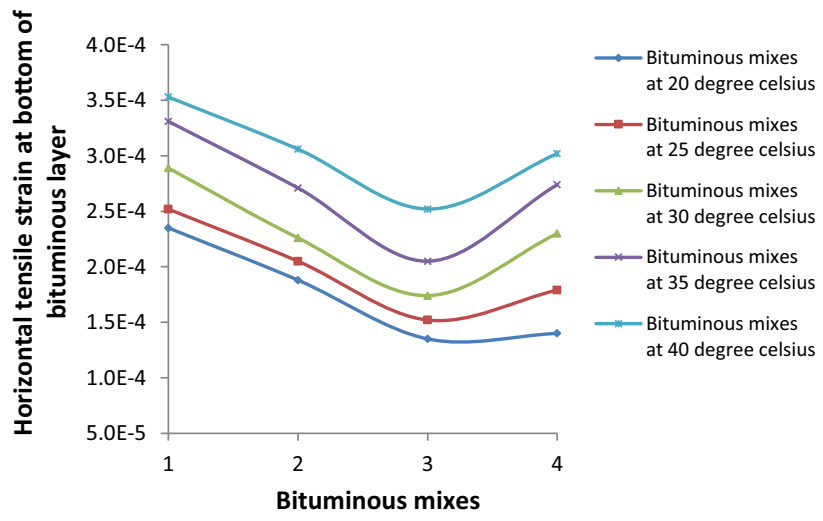

Fig. 2 Bituminous mixes vs horizontal tensile strain at the bottom of the bituminous layer 
In the present study, a program coded in FORTRAN is used for the two-dimensional analysis where the true pavement interaction is treated as an axisymmetric solid. From Fig. 3, it is clear that there is an average increase of $14.18 \%$ at a rise of temperature from 20 to $25{ }^{\circ} \mathrm{C}, 34.09 \%$ at a rise of temperature from 20 to $30{ }^{\circ} \mathrm{C}, 58.14 \%$ at a rise of temperature from 20 to $35{ }^{\circ} \mathrm{C}$ and $78.83 \%$ at a rise of temperature from 20 to $40{ }^{\circ} \mathrm{C}$ in horizontal tensile strain. For the modern trucks, which usually have more than $0.800 \mathrm{MPa}$ tire pressure, the right binder grade of bituminous layer (comprising bituminous concrete and dense bituminous macadam) is considered the same and is $1700 \mathrm{MPa}$ for $250 \mathrm{~mm}$-thick bituminous layer (Figs. 4, 5, $6,7)$. Drastic change in the value of the horizontal tensile strain at the bottom of the bituminous layer and vertical compressive strain on top of the subgrade is observed, when the stiffer binder of viscosity grade 40 is used. A reduction of 18.98 and $5.25 \%$ in horizontal tensile strain and vertical compressive strain, respectively, is observed at a $200 \mathrm{~mm}$ thickness of bituminous layer and reduction of 21.12 and $6.72 \%$ in the horizontal tensile strain and vertical compressive strain, respectively, at $250 \mathrm{~mm}$ thickness of bituminous layer. As the values of critical parameters are noticed well within the allowable limits at $200 \mathrm{~mm}$, it is concluded that the use of a stiffer binder for DBM makes the pavements safe for the selected temperature condition as far as fatigue of the bituminous layer and rutting in subgrade is concerned with the reduction in the thickness of the bituminous layer even at higher temperature. Further, it is observed that the use of waste plastic/rubber is found in safe limits at $250 \mathrm{~mm}$-thick bituminous layer for the selected condition. From the analysis, it is concluded that the use of too soft a bituminous mix results in lowering the structural capacity of the pavement at high temperatures and too hard bituminous mixes would become brittle at low temperatures resulting in cracking under loading.

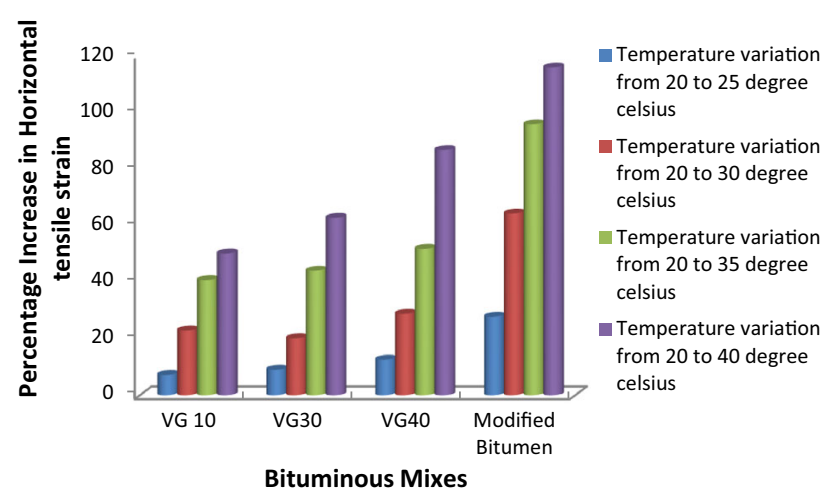

Fig. 3 Bituminous mixes vs percentage increase in horizontal tensile strain

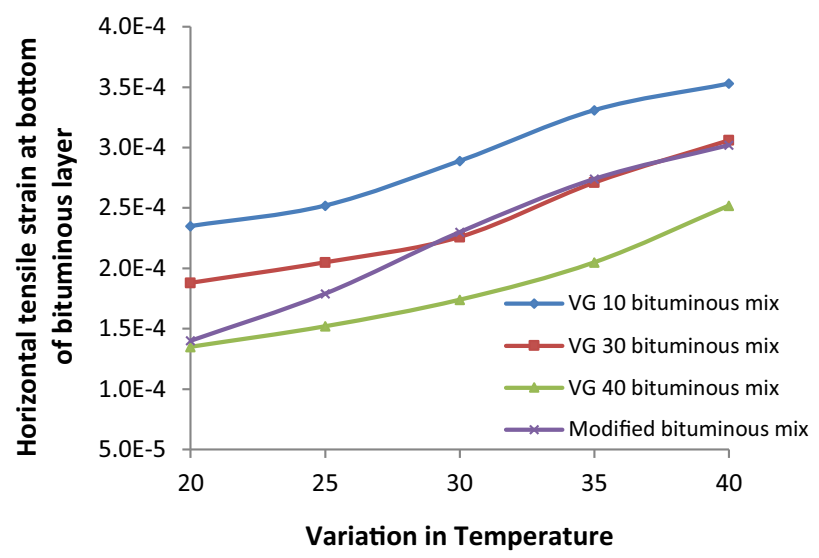

Fig. 4 Variation in temperature vs horizontal tensile strain at the bottom of the bituminous layer

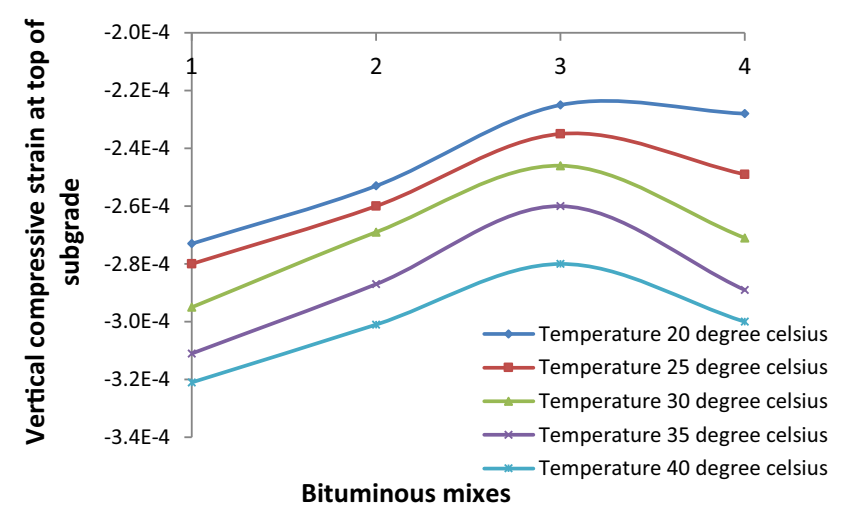

Fig. 5 Bituminous mixes vs vertical compressive strain at the top of the subgrade

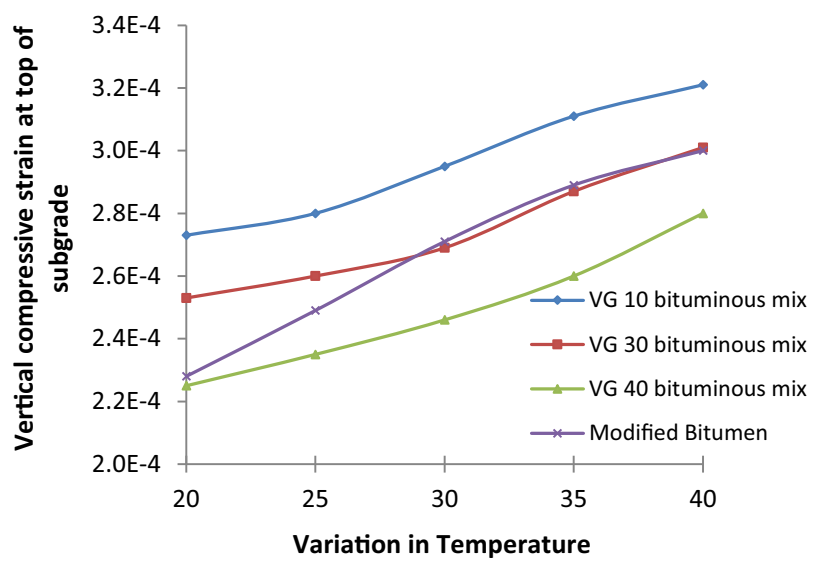

Fig. 6 Variation in temperature vs vertical compressive strain at the top of the subgrade

\section{Observations and conclusions}

- For the modern trucks, which usually have more than $0.800 \mathrm{MPa}$ tire pressure, the right binder grade of 


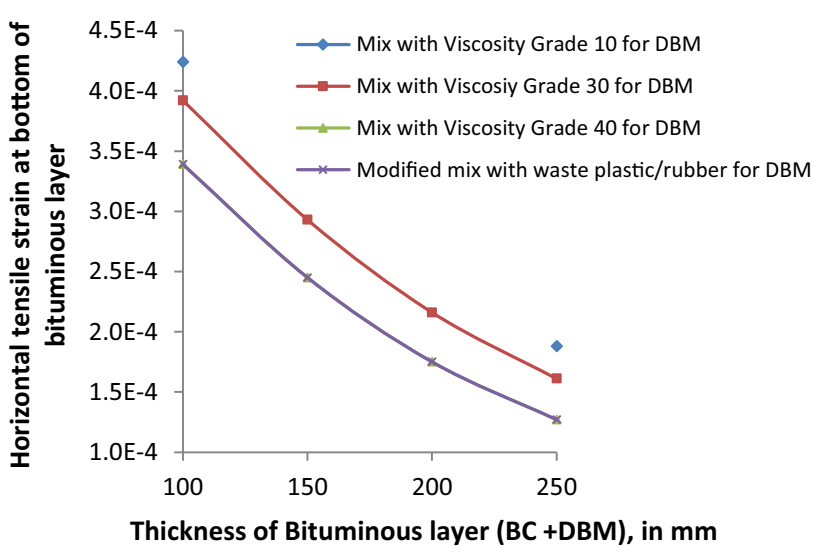

Fig. 7 Thickness of the bituminous layer vs horizontal tensile strain at the bottom of the bituminous layer

bituminous layer comprising a wearing course and DBM is $1700 \mathrm{MPa}$ for $250 \mathrm{~mm}$-thick bituminous layer.

- When stiffer binder is used, drastic change in the value of critical parameters is observed, and a reduction of 18.98 and $5.25 \%$ in horizontal tensile strain and vertical compressive strain, respectively, is observed at a $200 \mathrm{~mm}$ thickness of bituminous layer and around 21.12 and $6.72 \%$ in the horizontal tensile strain and vertical compressive strain, respectively, at $250 \mathrm{~mm}$.

- As the values of critical parameters are noticed well within the allowable limits at $200 \mathrm{~mm}$ thickness of bituminous layer, it is concluded that the use of a stiffer binder for DBM makes the pavements safe as far as fatigue of the bituminous layer and rutting in subgrade is concerned with the reduction in thickness of the bituminous layer even at higher temperature.

- It is observed that the use of waste plastic/rubber is found in safe limits at $250 \mathrm{~mm}$-thick bituminous layer for the selected condition.

- The use of too soft a bituminous mix results in lowering the structural ability of the pavement at high temperatures and too hard bituminous mixes would become brittle at low temperatures resulting in cracking under loading.
- The vertical compressive strain on top of the subgrade is well within the allowable limits set by the guidelines, showing safety against rutting for the selected trial pavement.

- Adverse effect is noticed on increase of temperature on the life of the pavement.

\section{References}

1. IRC SP: 53 Guidelines on the use of polymer and rubber modified bitumen in road construction. Specifications of Indian Roads Congress, India, 2002

2. Ranadive MS, Tapase AB (2013) Investigation of behavioral aspects of flexible pavement under various conditions by finite element method. Constitutive modeling of geomaterials, Springer, Berlin, pp 765-770. doi:10.1007/978-3-642-32814-5_ 100

3. Ranadive MS, Tapase AB (2012) Improvement in strength of flexible pavement: an experimental approach. J Environ Res Dev 6(3A):844-852

4. IRC: $37-2012$ Guidelines for the design of flexible pavements. Indian Roads Congress, New Delhi

5. Tapase A, Ranadive M (2016) Performance evaluation of flexible pavement using the finite element method. ASCE GSP Ser GeoChina 2016:9-17. doi:10.1061/9780784480090.002

6. Das A (2015) Analysis of pavement structures. CRC Press, Taylor and Francis Group, Boca Raton

7. American Association of State Highway and Transportation Officials AASHTO (1993) AASHTO guide for design of pavement structures. AASHTO, Washington, DC

8. Huang YH (2008) Pavement analysis and design. 2nd ed. Pearson Education, Inc and Dorling Kindersley Publishing, Inc

9. Zeevaert L (1982) Foundation engineering for difficult subsoil conditions. 2nd edition, Van Nostrand Reinhold company Inc

10. Zienkiewicz OC, Taylor RL (1991) The finite element method, vol 2. McGraw Hill, New York

11. Helwany S, Dyer J, Joeleidy (1998) Finite element analysis of flexible pavement. J Transp Eng ASCE 124(5):491-499. doi:10. 1061/(ASCE)0733-947X(1998)124:5(491))

12. Sinha AK, Chandra S, Kumar P (2014) Finite element analysis of flexible pavement with different subbase materials. Indian Highways New Delhi 42(2):53-63

13. NCHRP (2004) Guide for mechanistic-empirical design of new and rehabilitated pavement structures. National Cooperative Highway Research Program (NCHRP), Project 1-37A, Washington, DC 